\title{
Investigation of Seat Suspensions with Embedded Negative Stiffness Elements for Isolating Bus Users' Whole-Body Vibrations
}

\author{
Georgios Papaioannou - KTH Royal Institute of Technology \\ Dragan Sekulic - Chalmers University of Technology \\ Efstathios Velenis - Cranfield University \\ Ioannis Antoniadis - NTU of Athens
}

\begin{abstract}
Buses drivers are group at risk who often suffer from musculoskeletal problems, such as low-back pain, while bus passengers on the last row seats are experiencing accelerations of high-values. In this paper, the contribution of K-seat in decreasing the above is investigated with a detailed simulation study. The K-seat model, a seat with a suspension that functions according to the KDamper concept, which combines a negative stiffness element with passive one, is bench-marked against the conventional passive seat (PS) in terms of comfort when applied to different bus user's seats. More specifically, it is tested in the driver's and two different passenger's seats, one from the rear overhang and one from the middle part. For the benchmark's shake, both are optimized by applying excitations which correspond to real intercity bus floor responses when it drives over a real road profile. Then, a human model is placed to the seats in order to compare their optimum solutions in terms of user's whole-body vibrations, using objective comfort metrics. Based on the results, the K-Seat improves significantly the comfort of the users ( 92\%) compared to the PS, while it achieves similar decrease in the maximum values of the user's back accelerations ( $97 \%)$.
\end{abstract}

\section{Introduction}

Passengers and drivers, (i.e. vehicle users) in road, railway, air and waterway are experiencing vibrations, which generate the feeling of discomfort, affect working productivity and put human health in risk if they are intense [1]. Particularly, vehicle users ins various vehicle types (construction machinery, farm machinery, heavy-duty vehicles and buses) are a group in important risk [2], [3]. Regarding bus drivers, it is proven that they suffer from low back pain based on investigations of whole-body vibrations among professional drivers in various countries [4]-[8], which outlined musculoskeletal disorders as the most common health issues experiences by bus drivers. Similarly, passengers on the last row seats are exposed to high-value accelerations causing discomfort feeling, which has been validated by studies with experiments and simulations [9], [10].

Vibrations coming from bus floor to the driver's body are attenuated by both seat suspension system and cushion. In the case of bus passengers' seats, these vibrations are weakened by foam cushion only. In particular for buses, it was found that the seat position plays an important role on the intensity of the vibrations [9]. Another important factor is the construction properties of the seats and its dynamic characteristics. Much of work has been done in isolating vibrations using passive seat suspension system with linear characteristics of its elements (springs/dampers). It seems that such systems regardless of their optimizations have reached their full capacity [11]-[14]. In this respect, semi-active and active suspensions [15]-[18] have been investigated, but they are more expensive and complicated. Air ride seats have been studied regarding buses and trucks [19], [20]. However, studies have shown that the air suspension seat don't not perform well in the coach buses, transmitting $76-92 \%$ of the floor measured vibration to the seat of the operator in various buses [21]. In an attempt to improve further the isolation of vibrations, the last decade, the so-called negative stiffness suspension (NSS) with mechanisms combining negative stiffness elements with positive stiffness ones, have been introduced to seat suspensions. The negative stiffness elements are mechanical parts that are used in such way that they reduce the system's stiffness, which has a considerable influence on isolation effectiveness and can create a more susceptible to vibration system, but without decreasing the system load support capacity. As a result, in seat design, their main advantage is that they allow the combination of high static stiffness, for static comfort, with low dynamic stiffness, for ride comfort. In this work, the application of novel vibration isolators in specific seats of the bus, exposed to intense vibrations (driver's and rear row passengers' seat), will be investigated.

The most representative examples of such seat designs are the following. A passive vibratory isolation system [22] using negative stiffness structure was designed illustrating a wide frequency range of isolation with the resonance phenomenon almost not occurring. Later, an active damper was added [23] and tested. The effectiveness of this model was investigated experimentally [24] and further regarding its stiffness [25]. Another quasi-zero stiffness vibration isolator was designed [26] by using the conceptual design of cam-roller-spring mechanisms (CRSMs), in which the peak transmissibility and the starting frequency of the isolation never overshoots those of the linear counterpart no matter how large the excitation amplitude is. The conceptual design of cam-roller-spring mechanisms (CRSMs) was [27] applied for off-road vehicles with experimental validation of the theoretical solutions. A new type of seat suspension with a hollow composite rubber spring was developed [28], which can attenuate more effectively the low frequency from the uneven ground, and provide simultaneously a more stable support so that the driver can control the vehicle effectively. Recently, a novel vibration isolator (KDamper) was introduced in passenger vehicle seat [29], [30]. The novel seat suspension was benchmarked with the most common seat models in the literature and was proven to be superior in various types of analysis (comparison of optimized solutions, varying road input and passenger mass, investigation of seat-to-head transmissibility etc.).

In this work, K-seat, a seat with a suspension that functions according to the KDamper concept, which combines a negative stiffness element with passive one, is applied to three seats of an intercity bus positioned in the front, middle and rear part (driver, passenger 27 and passenger53 seats, Figure 1(b)). Since to the authors knowledge, Kseat solution has not been applied to the bus seats, and its performance has not yet been studied, the aim of this paper is to reveal whether it could contribute in decreasing low-back pain in the driver and high-level accelerations values experienced by the bus passengers in comparison to the conventional (passive) seat. In order to achieve these goals, K-seat and conventional passive seat models are first optimized in terms of their dynamic comfort for each bus 
user. In the optimization, the seat models are excited by bus floor responses of an intercity bus model driving in a real road roughness. The seats optimum design solutions for each user are applied to the models to assess the whole-body vibration (WBV) of bus users. For WBV assessment important seat comfort metrics proposed by standard ISO 2631/1997 are used. In this paper, firstly bus and seathuman models have been presented, secondly, configuration of the optimization procedure is displayed; thirdly, the optimization results are outlined, and the efficiency of the different seat models is compared; and finally, conclusions are extracted.

\section{Materials \& Methods}

For the purpose of this investigation, a validated model of an intercity bus is excited with a real road profile. Its floor responses in the positions of the driver and the two passengers (middle and rear end row) are used as excitations to the two seat models tested in this work. For their comparison, a seated human model is also applied, in order to investigate with detail, the whole-body vibrations using passenger and seat comfort metrics.

\section{Vehicle Model}

Regarding the vehicle model, a validated model of an intercity bus is used. Intercity bus has 53 passengers' seats, a seat for driver and a seat for assistant driver (Figure1). Model of this bus built in ADAMS/View software is presented in Figure 2. More details about the bus model and its validation could be found in the literature [10], [31]. Fully loaded intercity bus is considered in this investigation. Front axle suspension comprises two air springs and four telescopic shock absorbers. Rear axle suspension system includes four air springs and four telescopic shock absorbers. Linear characteristics of the springs and the shock absorbers are defined by SPRINGDAMPER elements (Figure 2) from ADAMS/View library.

Figure 2 also shows three markers, one on the bus floor below driver's seat and two below passenger's 27 and passenger's 53 seat (seat in the middle and last row, respectively). These markers illustrate the points from which the bus floor vertical displacement, velocity and acceleration signals are collected in order to serve as inputs in the seat-human system. Table 1 presents the natural frequencies of important DOF of the bus model i.e. the roll, pitch and heave for the sprung mass; the roll and heave for the front/rear axles.

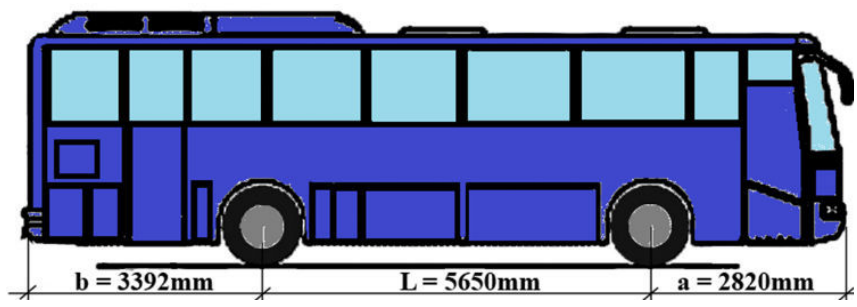

(a)

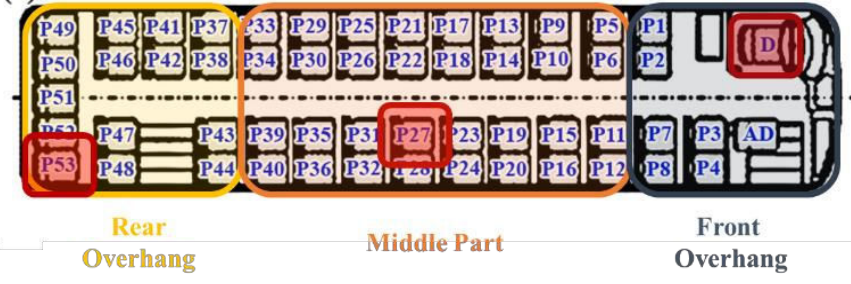

(b)

Figure 1. Intercity bus: (a) L-wheelbase; a-front overhang; b-rear overhang); (b) Front and rear overhang, and middle part [31].

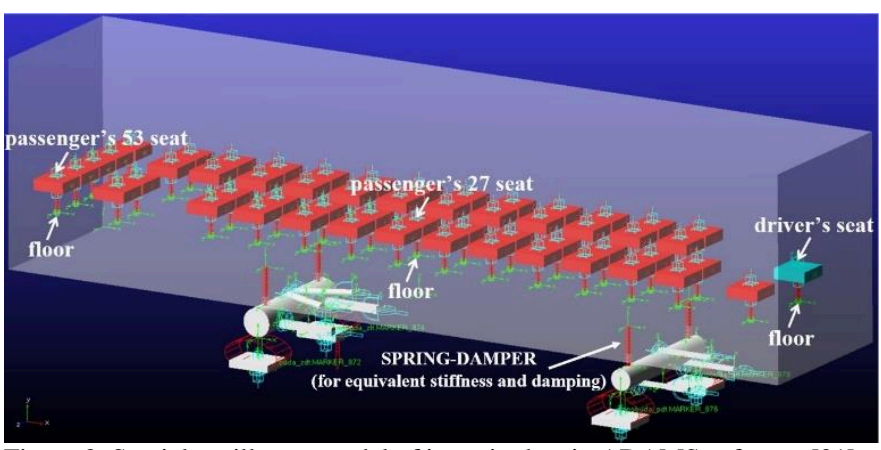

Figure 2. Spatial oscillatory model of intercity bus in ADAMS software [31]

\section{Seat Models}

The overall occupant ride quality in automotive engineering takes in consideration multiple factors, such as the chassis design (i.e. suspension systems), the interior configuration (cabin temperature and the various ergonomics aspects), etc. In this work, we investigate the seat design, as the suspension system installed below the seating surface can offer significant levels of the whole-body vibration isolation.

Table 1. Natural frequencies of important DOF in the bus model

\begin{tabular}{|c|c|c|c|}
\hline DOF of Sprung Mass & $\omega(\mathrm{Hz})$ & DOF of Axle & $\omega(\mathbf{H z})$ \\
\hline Roll $\left(\omega_{\varphi \mathrm{s}}\right)$ & 0.69 & Roll $\left(\right.$ front $\left.-\boldsymbol{\omega}_{\boldsymbol{\varphi f u}}\right)$ & 2.74 \\
\hline Pitch $\left(\omega_{\boldsymbol{\theta} \mathrm{s}}\right)$ & 0.74 & Heave $\left(\right.$ front $\left.-\boldsymbol{\omega}_{\mathrm{zfu}}\right)$ & 6.79 \\
\hline \multirow{2}{*}{ Heave $\left(\omega_{\mathrm{zs}}\right)$} & \multirow{2}{*}{1.19} & Roll $\left(\right.$ rear $\left.-\boldsymbol{\omega}_{\varphi \mathrm{ru}}\right)$ & 5.24 \\
\cline { 3 - 4 } & & Heave $\left(\right.$ rear $\left.-\boldsymbol{\omega}_{\mathrm{zru}}\right)$ & 9.03 \\
\hline
\end{tabular}

\section{Passive Seat Model (PS)}

The most common seat model includes a spring $\left(K_{\mathrm{v}}\right)$ and a damper $\left(C_{\mathrm{v}}\right)$ (Figure 3). The equations of are presented in Equation 1:

$m_{s e} \ddot{z}_{s e}+C_{\mathrm{v}} \cdot\left(\dot{z}_{s e}-\dot{z}_{s}\right)+K_{\mathrm{v}} \cdot\left(z_{s e}-z_{s}\right)=0$

where $m_{s e}(\mathrm{~kg})$ is the total seat mass including the seat structure and the foam $\left(m_{s e}=13.6 \mathrm{~kg}\right) ; \mathrm{z}_{\mathrm{S}}(m)$ is the vertical displacement of the vehicle body and $\dot{z}_{s}(\mathrm{~m} / \mathrm{s})$ velocity; $\mathrm{z}_{\mathrm{se}}(\mathrm{m})$ is the vertical displacement seat with $\dot{z}_{s e}(\mathrm{~m} / \mathrm{s})$ and $\ddot{z}_{s e}\left(\mathrm{~m} / \mathrm{s}^{2}\right)$ its velocity and acceleration, respectively. The $z_{s}$ and $\dot{z}_{S}$ are the excitations for suspension system of the seat and represent the bus floor responses.

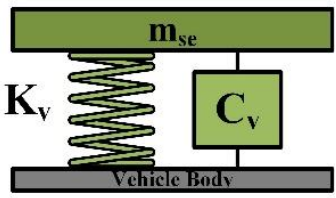

Figure 3. 1-DOF passive suspension system (PS)

\section{K-Seat Model}

KDamper is a passive suspension combining appropriate stiffness elements and a negative stiffness (NSS) element, which has been applied in seats in the latest work of Papaioannou et al [29] and is described extensively. The K-Seat (Figure 4) consists of the total seat mass $\left(m_{s e}\right)$ which is supported by two parallel linear springs ( $K_{S}$ and $\left.K_{\mathrm{v}}\right)$ and a damper $\left(C_{\mathrm{v}}\right)$. The damper $\left(C_{\mathrm{v}}\right)$ and the spring $\left(K_{\mathrm{v}}\right)$ are also connected to a smaller mass $\left(m_{d}\right)$. The two symmetrical horizontal 
springs $\left(K_{S}\right)$ form the negative stiffness and they support the internal mass $\left(m_{d}\right)$. Figure 4 presents the position of the static equilibrium of the system after applying the gravity force (Left). The disturbed position, which occurs when excitation of the $m$ mass is applied, is shown in Figure 4 (Right).

The differential equations describing the motion of the system are as follows:

$m_{s e} \ddot{z}_{s e}+C_{\mathrm{v}}\left(\dot{z}_{s e}-\dot{y}\right)+K_{S}\left(z_{s e}-z_{s}\right)+K_{\mathrm{v}}\left(z_{s e}-y\right)=0$

$m_{d} \ddot{y}-C_{\mathrm{v}}\left(\dot{z}_{s e}-\dot{y}\right)-K_{\mathrm{v}}\left(z_{s e}-y\right)+f_{N D}\left(u-z_{s}\right)=0$

where $y$ is the vertical displacement of the internal mass $\left(m_{d}\right)$ and $\dot{y}$ its velocity. The total negative force of the mechanism applied in the inner mass $\left(f_{N D}\right)$ with regards to its distance from the horizontal springs $\left(u=u_{0}+y\right)$ is evaluated according to Equation 4:

$f_{N D}(u)=f_{N}(u)-f_{N}\left(u_{0}\right)=f_{N}(u)-f_{N 0}$

where $f_{N 0}$ is the force applied at the initial position $u_{0}$; and $f_{N}$ the dynamic negative force. The $u_{o}$ is a small value $(1 \mathrm{~mm})$ to make the response symmetrical around the equilibrium, while the inner mass $\left(m_{d}\right)$ is selected at $1 \mathrm{~kg}$ (i.e $\sim 1 \%$ of $m$ mass) according to previous works [32]. Based on the above, $f_{N}$ can be described as follows considering it is originated by the two symmetrical and horizontal springs $\left(K_{h}\right)$.

$f_{N}(u)=-2 K_{h}\left(1+\frac{L_{o}-a_{o}}{\sqrt{b^{2}-u^{2}}}\right) u=-2 K_{h}\left(1+c_{I} \frac{1}{\left(1-\frac{u^{2}}{b^{2}}\right)^{\frac{1}{2}}}\right) u$

where $a_{0}$ is distance from the wall, b the bar length, $L_{o}$ is the initial length of $K_{h}$ when underformed; $L_{h}$ is the length of $K_{h}$ and is defined as:

$L_{h}=a_{o}-\sqrt{\left(b^{2}-u^{2}\right)}$

while a coefficient is defined as:

$c_{I}=\frac{L_{o}-a_{o}}{b}$

where when $c_{I}=0$ the two horizontal springs are equivalent to a negative spring with constant stiffness $K_{N}=-2 K_{h}$. The final equations are shown below:

$m_{s e} \ddot{z}_{s e}+C_{\mathrm{v}}\left(\dot{z}_{s e}-\dot{y}\right)+K_{S}\left(z_{s e}-z_{s}\right)+K_{\mathrm{v}}\left(z_{s e}-y\right)=0$

$$
\begin{aligned}
& m_{d} \ddot{y}-C_{\mathrm{v}}\left(\dot{z}_{s e}-\dot{y}\right)-K_{\mathrm{v}}\left(z_{s e}-y\right) \ldots \\
& -2 K_{h}\left[1+c_{I}\left(\frac{1}{\sqrt{1-\frac{\left(u_{o}+y-z_{s}\right)^{2}}{b^{2}}}}\right)\right]\left(u_{o}+y-z_{s}\right) \ldots \\
& +2 K_{h}\left[1+\left(\frac{c_{I}}{\sqrt{1-\frac{u_{o}^{2}}{b^{2}}}}\right)\right] u_{o}=0
\end{aligned}
$$

Regarding the manufacturing perspective of the current design, there might be a singular point when the dummy mass $\left(m_{d}\right)$ moves at certain displacement $(y)$, and the left and right horizontal $\left(K_{h}\right)$ springs may not always deform equally. This might happen especially when the left and right horizontal springs are not perfectly the same, which should be aimed as it has been done in this work. The result of such cases will be the K-seat to not function properly and if the vibration from the base is large enough, it may be diverged.

\section{Human Body Model}

The human body is more vulnerable to vibrations when it is in seated position and is induced in low-frequency excitation, i.e. random road profiles. As a result, the study of the biomechanical response of seated human body parts is an important research area in automotive field. In this work, the human body is modeled (Figure 5) [33]-[35], in order to assess the overall passenger comfort. The differential equations of motions are described in Equation 11-18 for coupling the human body model with the different seat models. For the derivation of the equations, the assumption of the human body always contact with the seat is considered. Regarding the coupling of the models, Equation 11a is used for coupling PS-Seat with the human body (Equations 12-18), while Equations $11 \mathrm{~b}$ and $11 \mathrm{c}$ are used for coupling the K-seat with the human body (Equations 12-18).-The parameters used as well as the natural frequencies of each segment of the human body model are illustrated in Table 2.

PS-Seat:

$\overline{m_{s e} \ddot{z}_{s e}}+C_{\mathrm{v}}\left(\dot{z}_{s e}-\dot{z}_{s}\right)+K_{\mathrm{v}}\left(z_{s e}-z_{s}\right)-c_{s e}\left(\dot{z}_{s}-\dot{z}_{s e}\right)-$

$k_{s e}\left(z_{8}-z_{s e}\right)-c_{8}\left(\dot{z}_{8}-\dot{z}_{s e}\right)-k_{8}\left(z_{8}-z_{s e}\right)=0$

$\underline{\text { K-Seat: }}$

$m_{s e} \ddot{z}_{s e}+C_{\mathrm{v}}\left(\dot{z}_{s e}-\dot{y}\right)+K_{\mathrm{s}}\left(z_{s e}-z_{s}\right)+K_{v}\left(\mathrm{z}_{s e}-y\right)$

$-c_{8}\left(\dot{z}_{8}-\dot{z}_{s e}\right)-k_{8}\left(z_{8}-z_{s e}\right)=0$

$m_{d} \ddot{y}-C_{\mathrm{v}}\left(\dot{z}_{s e}-\dot{y}\right)-K_{\mathrm{v}}\left(z_{s e}-y\right)+f_{N D}\left(u-z_{s}\right)=0$

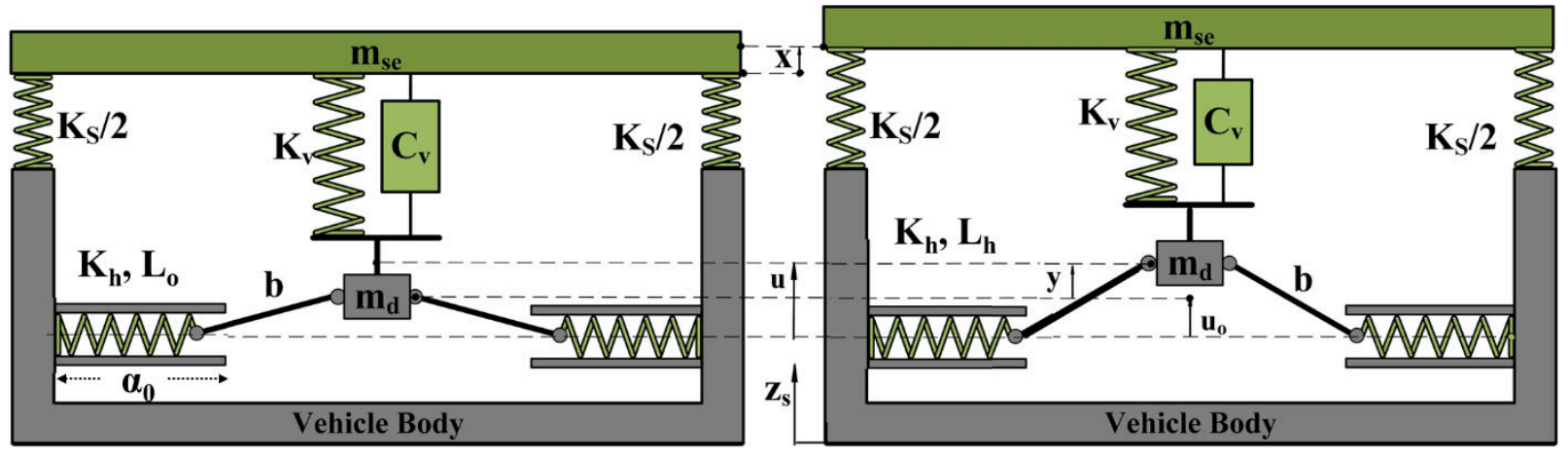

Figure 4. K-Seat suspension model (Left) at the equilibrium position and (Right) at a random position $x$ 
Pelvis:

$\overline{m_{8} \ddot{z}_{8}}-c_{2}\left(\dot{z}_{2}-\dot{z}_{8}\right)-k_{2}\left(z_{2}-z_{8}\right)-c_{7}\left(\dot{z}_{7}-\dot{z}_{8}\right)-k_{7}\left(z_{7}-z_{8}\right) \ldots$

$+c_{8}\left(\dot{z}_{8}-\dot{z}_{s e}\right)+k_{8}\left(z_{8}-z_{s e}\right)=0$

Abdomen:

$\overline{m_{7} \ddot{z}_{7}+c_{7}}\left(\dot{z_{7}}-\dot{z_{8}}\right)+k_{7}\left(z_{7}-z_{8}\right)-c_{6}\left(\dot{z}_{6}-\dot{z}_{7}\right)-k_{6}\left(z_{6}-z_{7}\right)$

$=0$

Diaphragm:

$\overline{m_{6} \ddot{z}_{6}+c_{6}}\left(\dot{z}_{6}-\dot{z}_{7}\right)+k_{6}\left(z_{6}-z_{7}\right)-c_{5}\left(\dot{z_{5}}-\dot{z}_{6}\right)-k_{5}\left(z_{5}-z_{6}\right)$

$=0$

Thorax:

$\overline{m_{5} \ddot{z}_{5}}+c_{5}\left(\dot{z_{5}}-\dot{z_{6}}\right)+k_{5}\left(z_{5}-z_{6}\right)-c_{4}\left(\dot{z_{3,4}}-\dot{z_{5}}\right)-k_{3}\left(z_{3,4}-z_{5}\right)$

$=0$

Torso:

$\overline{m_{3,4} \ddot{z}_{3,4}}+c_{4}\left(\dot{z}_{3,4}-\dot{z_{5}}\right)+k_{4}\left(z_{3,4}-z_{5}\right)-c_{3}\left(\dot{z}_{3,4}-\dot{z}_{2}\right)$

$-k_{3}\left(z_{3,4}-z_{2}\right)=0$

Back:

$m_{2} \ddot{z}_{2}-c_{3}\left(\dot{z}_{3,4}-\dot{z}_{2}\right)-k_{3}\left(z_{3,4}-z_{2}\right)+c_{2}\left(\dot{z}_{2}-\dot{z}_{8}\right)+k_{2}\left(z_{2}-z_{8}\right)$

$=0$

Head:

$\underline{m_{1} \ddot{z}_{1}}+c_{1}\left(\dot{z_{1}}-\dot{z_{2}}\right)+k_{1}\left(z_{1}-z_{2}\right)=0$

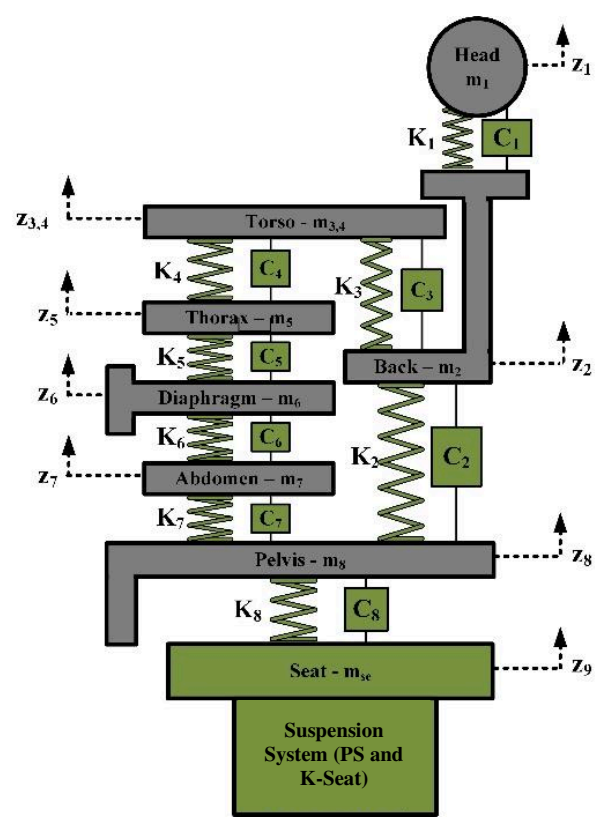

Figure 5. Seat-human model

\section{Excitations}

In this work, the excitations used consist of the ones applied to the bus model and the ones used for the excitation of the seat-human system. More specifically, a real random road profile is used as excitation in the bus model. Then, the floor responses in the driver's, passenger27's and passenger53's seat position are used to excite the seat-human models.

Table 2. The parameters of the m-C-K systems, which shape the seat and human models.

\begin{tabular}{|c|c|c|c|c|}
\hline & $\mathbf{m}[\mathrm{kg}]$ & $\mathrm{C}_{\mathrm{i}}[\mathrm{N} . \mathrm{s} / \mathrm{m}]$ & $K_{\mathbf{i}}[\mathbf{N} / \mathbf{m}]$ & $\omega_{\mathrm{i}}(\mathrm{Hz})$ \\
\hline Pelvis $\left(m_{8}\right)$ & 27.70 & 378 & 25500 & 1.99 \\
\hline $\operatorname{Abdomen}\left(m_{7}\right)$ & 6.20 & 298 & 894 & 2.72 \\
\hline Diaphragm $\left(m_{6}\right)$ & 0.46 & 298 & 894 & 4.89 \\
\hline Thorax $\left(m_{5}\right)$ & 1.36 & 298 & 894 & 7.73 \\
\hline Torso $\left(m_{3-4}\right)$ & 33.33 & 298 & 894 & 10.53 \\
\hline Back $\left(m_{2}\right)$ & 6.94 & 3651 & 53460 & 12.81 \\
\hline $\operatorname{Head}\left(m_{1}\right)$ & 5.50 & 3651 & 53460 & 26.76 \\
\hline Seat $\left(m_{s e}\right)$ & 13.60 & \multicolumn{3}{|c|}{ To be optimized } \\
\hline \multicolumn{5}{|c|}{ Human's Mass $=\sum_{i=1}^{8} m_{i}=81.54 \mathrm{~kg}$} \\
\hline
\end{tabular}

Firstly, regarding the bus excitations, real road roughness signal had been used as bus model excitation (Figure 6). The road roughnesses are recorded along two tracks on every $0.15 \mathrm{~m}$ of longitudinal distance with laser transducer at the speed $80 \mathrm{~km} / \mathrm{h}$ (Figure 6a). It could be noticed that roughness intensities on low frequencies (below $2 \mathrm{~Hz}$ ) prevailing (Figure 6b). Excitation signals had been presented in ISO-8608 standard (Figure 6c). Road roughness could be categorized as averaged (C-level) for low spatial frequencies. On higher frequencies (above 1 cycles $/ \mathrm{m}$ ) road signal could be categorized as $\operatorname{good}(\mathrm{B}-\mathrm{level})$.

Secondly, regarding the seat excitations, Figure 7 (a, b) shows signals of the bus floor vertical displacements and velocities below driver's, passenger53's and passenger27's seats. These signals have been used as inputs in the seat-human models (Figure 5) referring to $z_{s}$ and $\dot{z}_{s}$. For most of the simulation time vertical displacements are not in the phase because of the pitch motion of the bus body. Figure 7(c) shows the accelerations in the same positions. The values of vertical accelerations for the bus floor below passenger's 53 seat, are ranged between. $\pm 20 \mathrm{~m} / \mathrm{s}^{2}$. These peak acceleration values are due to the bus passing over the $4 \mathrm{~cm}$ high localized bump, as shown in Figure 6(a).

\section{Performance Metrics}

\section{Ride Comfort}

Ride comfort (RC) is assessed via the root mean square (RMS) of the weighted vertical acceleration occurred on the seat. More specifically, the RC is evaluated according to Equation 19:

$R C_{i}=R M S\left(\ddot{z}_{w i}\right)=\left[\frac{1}{T}\left(\int_{0}^{T} \ddot{z}_{w i}(t)^{2} d t\right)\right]^{\frac{1}{2}}$

where $T$ is simulation time (s); $\ddot{z}_{w i}$ is the weighted vertical acceleration $\left(\mathrm{m} / \mathrm{s}^{2}\right)$ in time domain; and $i$ refers to a segment of the human body and the seat.

Since human body sensitivity on vibration depends on the frequency, standard ISO 2631 suggests frequency weighting curves for principal and additional weightings, shown in Figure 8, which are applied based on Equation 20. 
$Z_{w_{i}}=W P_{i_{1}} * W A_{i_{2}} * Z_{i}$

where $Z_{i}$ is the measurements $\left(\ddot{z}_{i}\right)$ transformed in the frequency domain; WP (Figure 8a) are the required principal frequency weighting curves for related to health, comfort and perception depicting the weighting frequency either for the $\mathrm{z}$ direction and for vertical recumbent direction except the head $\left(i_{1}=k\right)$; and WA (Figure $8 b$ ) is the additional frequency weightings according to the type of measurements or the location, more specifically related to (a) seat back measurements $\left(i_{2}=c\right)$, (b) measurements for rotational vibrations $\left(i_{2}=e\right)$, (c) measurement of vibration under the head of recumbent person $\left(i_{2}=j\right)$. In this work, the focus is on vibrations in the vertical direction, therefore $W k$ is used for WP when assessing bus users' comfort, while for WA no additional frequency weighting curves were applied in this work. Also, no multiplying factors have been applied.

Table 3. Comfort criteria in public means of transport

\begin{tabular}{|c|c|}
\hline Vibration intensity $\left[\mathbf{m} / \mathbf{s}^{\mathbf{2}}\right]$ & Comfort assessment \\
\hline$<0.315$ & comfortable \\
\hline $0.315-0.63$ & a little uncomfortable \\
\hline $0.5-1.0$ & fairly uncomfortable \\
\hline $0.8-1.6$ & uncomfortable \\
\hline $1.25-2.5$ & very uncomfortable \\
\hline$>2.0$ & extremely uncomfortable \\
\hline
\end{tabular}

Standard ISO-2631/1997 suggests comfort criteria inside the means of public transport (Table 3). These criteria have been used in this paper for assessing bus users ride comfort. Sometimes, the RC metric may underestimate the vibrations effects (high crest factors, occasional shocks and transient vibration). At these cases, the Vibration Dose Value (VDV) and Maximum Transient Vibration Value (MTVV) of the measurements should be calculated (Equation 21 and 22 respectively).

$M T V V_{\iota}=\max \left(\ddot{z}_{i}(t)\right)$

$V D V_{i}=\left[\int_{0}^{\tau} \ddot{z}_{i}(t)^{4} d t\right]^{\frac{1}{4}}$

The VDV metric is more sensitive to the acceleration peaks compared to the RC parameter, as it considers the fourth power of the weighted vertical acceleration. Thus, it is advised to be used in cases where the excitation applied to the human body involves many peaks.

\section{Seat Comfort}

The primary contact point for transmitting whole-body vibration (WBV) to the vehicle users (drivers and passengers) is via the seat suspension, which amplifies or attenuates the vibration from the vehicle floor. The seat's efficiency capabilities are related to the vibration spectrum and the seat dynamics, while in order to quantify it various metrics are used. In this work, the transmissibility and the seat effective amplitude transmissivity will be investigated.

\section{Transmissibility (TR)}

The transmissibility (TR) is used for the dynamic characteristics of a seat, which is a non-dimensional ratio of the seat surface vibration to

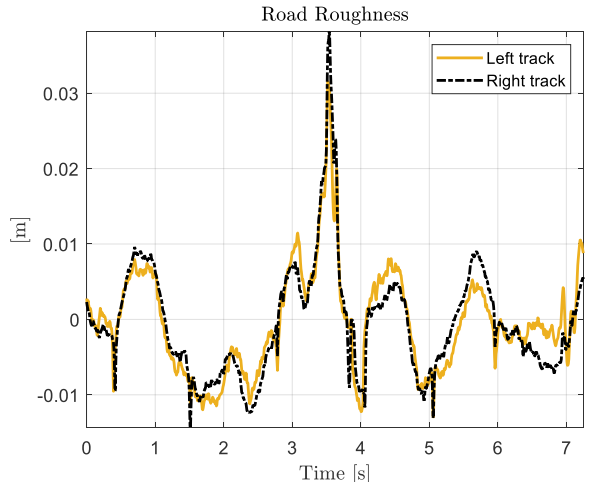

(a)

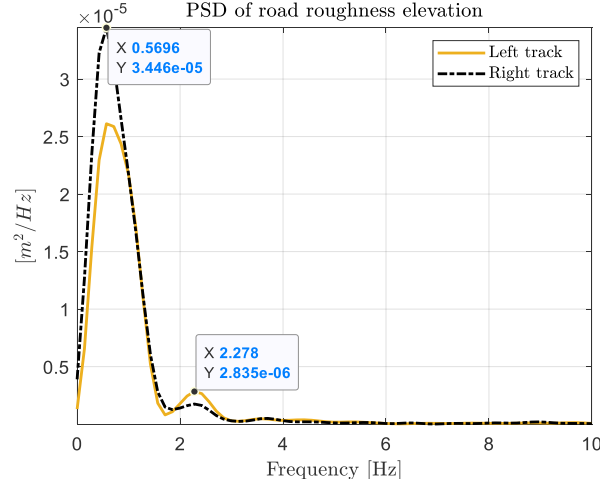

(b)

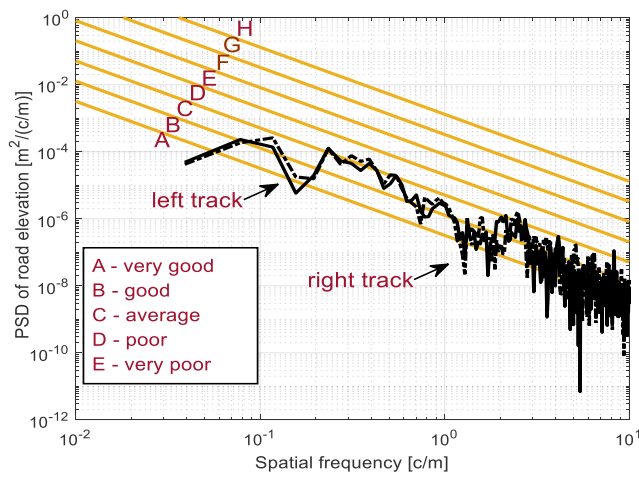

(c)

Figure 6. Road roughness signals in function of (a) time; (b) frequency; (c) spatial frequency according to standard ISO 8608

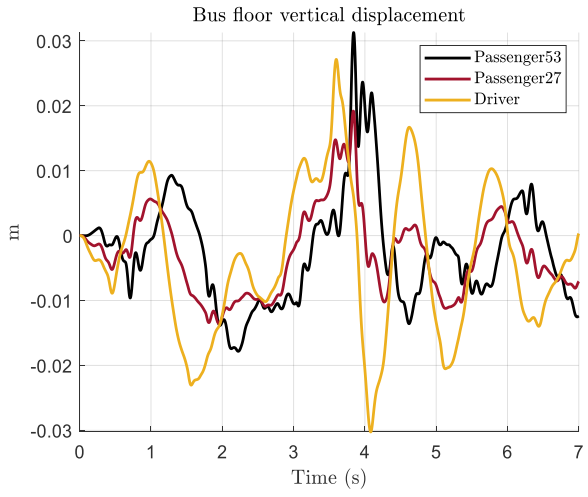

(a)

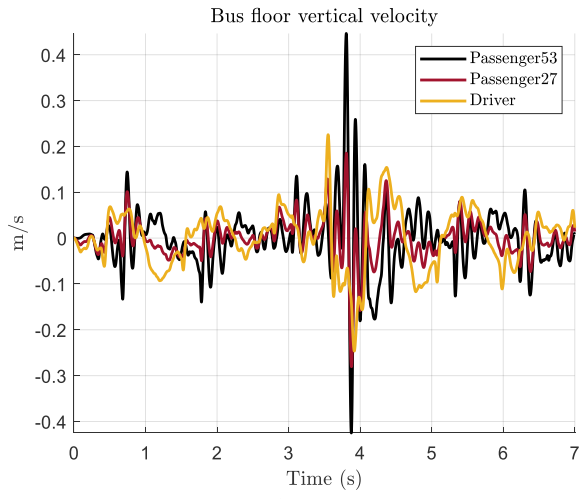

(b)

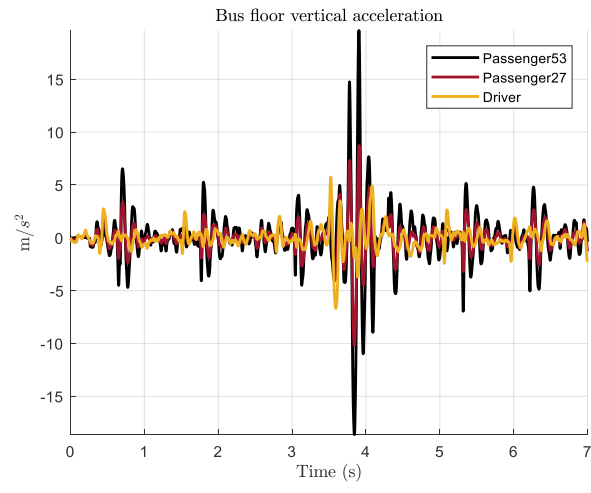

(c)

Figure 7. Bus floor vertical: (a) displacements; (b) velocities; and (c) accelerations in time domain. 


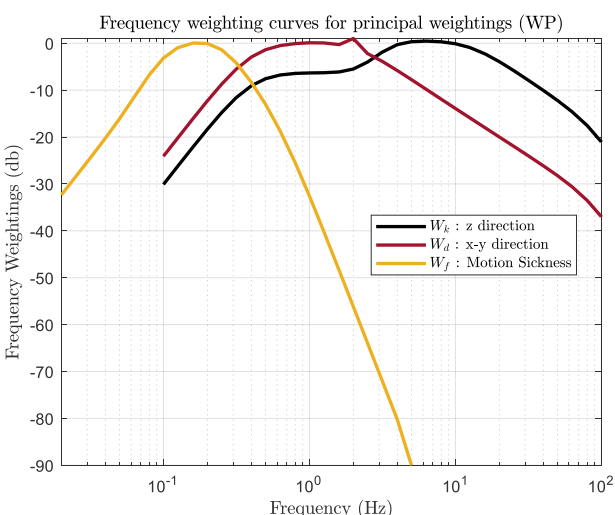

(a)

Figure 8. Frequency weighting curves for: (a) principal and (b) additional weighting

the seat base vibration (vehicle body or chassis floor). TR can be used to quantify seat performance. More specifically, in biomechanical systems, researchers of WBV consider the TR for assessing the perceived vibration of seated people in cases of singleinput/single-output motions, which is presented in Equation 23

$T R=\frac{\ddot{z}_{i}}{\ddot{z}_{\text {input }}}$

where $\ddot{z}_{i}$ is the response of the $\mathrm{i}^{\text {th }}$ subsystem $\left(\mathrm{m} / \mathrm{s}^{2}\right)$; and $\ddot{z}_{\text {input }}$ is an excitation $\left(\mathrm{m} / \mathrm{s}^{2}\right)$. In our case, the $\mathrm{i}^{\text {th }}$ subsystem will be the pelvis of the human body $\left(\mathrm{m}_{8}\right)$ and the input the bus floor vibrations.

\section{Seat Effective Amplitude Transmissibility (SEAT)}

The assessment of the dynamic seat comfort can also be done by the SEAT metric [36], [37] which is an objective measure used to compare isolation characteristic of the seats equipped with different suspension systems and excited with the same input signals, as shown in Equation 24.

$S E A T_{R C}=\frac{R C_{s e}}{R C_{\text {floor }}}$

Standard ISO 2631/1997 recommends also VDV for assessing the parameter SEAT when acceleration signal contains pronounced peaks, as shown in Equation 25.

$S E A T_{V D V}=\frac{V D V_{s e}}{V D V_{\text {floor }}}$

Based on SEAT values, the seat amplifies bus floor vibrations (SEAT $>1)$; the seat does not isolate floor vibration (SEAT $=1$ ), and there is no improvement in ride comfort; the seat attenuates some vibration $($ SEAT $<1)$.

\section{Optimization}

Various research studies have focused on suppressing or overcoming the conflict between the isolation of WBV and the load support capabilities of the seat. Recently, the focus has been turned on mechanisms which combine a NSS element with a positive stiffness element. However, the design of novel suspension systems is not enough, as their optimization is a crucial part in their design in order to secure the occupant dynamic and the static comfort. In this work, two seat suspension models (PS and K-seat) will be applied to the

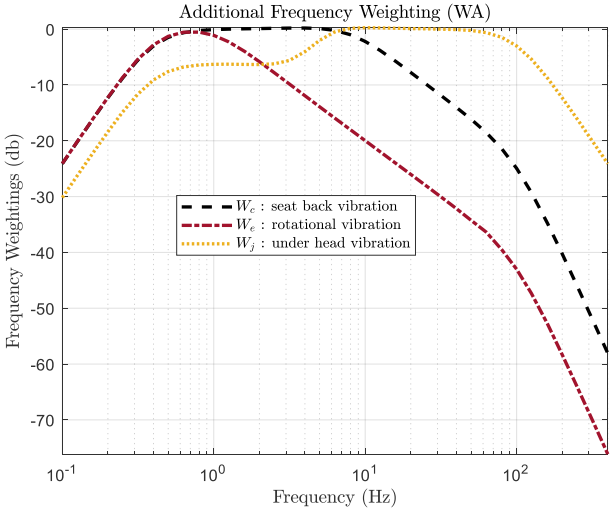

(b)

seats of a bus in three positions (driver, passenger27 and passenger53) and will be compared regarding their efficiency. For the sake of the comparison, the seat suspension systems in each position will be optimized in terms of their dynamic comfort.

\section{Objective Function}

The objective function selected to represent the dynamic comfort of the seats is the RC metric, shown in Equation 26, in the pelvis of the seated human.

$f_{1}=R C_{8}$

\section{PS - Design Variables, Bounds and Constraints}

Design variables $\left(K_{\mathrm{v}}\right.$ and $C_{\mathrm{v}}$ ) and their bounds for PS are shown in Table 4. Constraints are selected to ensure that the levels of comfort are acceptable (Constraint 1) and maintain the deformation of the system at low levels (Constraint 2) at the initial position, when the passenger load is applied (Table 5).

\section{K-Seat - Design Variables, Bounds and Constraints}

The next optimization scenario involves the optimization of the KSeat Model. The design variables (Table 6) ensure the suspension performance $\left(K_{\mathrm{S}}, K_{\mathrm{v}}, K_{h}\right.$ and $\left.C\right)$, the "negative" function of the mechanism and the dimensions of the structure $\left(a_{o}, L_{o}\right.$ and $\left.b\right)$ (Table 6). As far as the constraints are concerned (Table 7), except the ones which have been applied to the PS-Model (Constraints 1 and 2), the range of $\mathrm{c}_{\mathrm{I}}$ is limited to low levels $\left(-0.1<\mathrm{c}_{\mathrm{I}}<0.1\right)$, in order to secure the linear behavior of the suspension system and offer a more stable design.

Table 4. Design Variables for PS Model

\begin{tabular}{|c|c|c|c|c|c|}
\hline$\#$ & Lower Bounds (LB) & \multicolumn{3}{|c|}{ Design Variable } & Upper Bounds (UB) \\
\hline 1 & 300 & \multirow{2}{*}{$<$} & $C_{v}[N s / m]$ & \multirow{2}{*}{$<$} & 2500 \\
\hline 2 & 10000 & & $K_{\mathrm{v}}[N / m]$ & & 150000 \\
\hline
\end{tabular}

Table 5. Constraints for PS model

\begin{tabular}{|l|l|}
\hline$\#$ & Constraint \\
\hline $\mathbf{1}$ & $\mathrm{f} 1<1 \mathrm{~m} / \mathrm{s}^{2}$ \\
\hline $\mathbf{2}$ & $\mathrm{X}_{\mathrm{ST}}<0.1 \mathrm{~m}$ \\
\hline
\end{tabular}


Table 6. Design Variables for K-Seat Model

\begin{tabular}{|c|c|c|c|c|c|}
\hline \# & Lower Bounds (LB) & \multicolumn{3}{|c|}{ Design Variable } & Upper Bounds (UB) \\
\hline 1 & 0.1 & \multirow{7}{*}{$<$} & $\alpha_{o}[m]$ & \multirow{7}{*}{$<$} & 0.4 \\
\hline 2 & 0.1 & & $L_{o}[m]$ & & 0.4 \\
\hline 3 & 0.1 & & $b[m]$ & & 0.4 \\
\hline 4 & 300 & & $C_{\mathrm{v}}[N s / m]$ & & 1000 \\
\hline 5 & 10000 & & $K_{S}[N / m]$ & & 180000 \\
\hline 6 & 2000 & & $K_{P}[N / m]$ & & 70000 \\
\hline 7 & 2000 & & $K_{h}[N / m]$ & & 70000 \\
\hline
\end{tabular}

Table 7. Constraints for K-Seat Model

\begin{tabular}{|l|l|}
\hline$\#$ & Constraint \\
\hline $\mathbf{1}$ & $\mathrm{f} 1<1 \mathrm{~m} / \mathrm{s}^{2}$ \\
\hline $\mathbf{2}$ & $\mathrm{X}_{\mathrm{ST}}<0.1 \mathrm{~m}$ \\
\hline $\mathbf{3}$ & $-0.1<\mathrm{c}_{\mathrm{I}}<0.1$ \\
\hline
\end{tabular}

\section{Results}

The aim of the current work is to investigate the efficiency of the Kseat model in decreasing the low-back pains experienced by the bus drivers and the high acceleration values experienced by the passengers. The two seat designs (PS and K-Seat) are optimized in terms of their dynamic comfort and important parameters for both seats' designs are compared. Table 8 depicts the $R C_{i}$ and the MTVV of the vertical accelerations in the back and the seat, alongside with the SEAT $_{\text {RMS }}$ and the SEATVDv values. Figure $9(b, d, f)$ and Figure 9(c, e, g) comparatively show pelvis acceleration TR from bus floor and pelvis vertical accelerations in frequency domain for the two seat designs, respectively. Figure 10 comparatively presents the seat vertical accelerations for both seat designs in the position of each user, while Figure 11 comparatively shows users' back relative displacement for two seat models. Table 9 and 10 illustrate the optimum design variables in relation with their lower (LB) and upper (UP) bounds for each seat position for both seats.

Figure 9(a) shows bus floor vertical accelerations below each users' seat in frequency domain. Acceleration intestines are the highest values for the bus floor below passenger53's seat above $2 \mathrm{~Hz}$, whereas for the frequencies below $2 \mathrm{~Hz}$, acceleration intestines are the highest values for bus floor at the front part (below driver's seat). In the low value frequency range $(<2 \mathrm{~Hz})$, dominant frequency is $0.71 \mathrm{~Hz}$, which is close to the bus body pitch natural frequency 0.74 $\mathrm{Hz}$ (Table 1). At the higher frequency range $(>2 \mathrm{~Hz})$, dominant frequency for bus floor at each users' position is $7.85 \mathrm{~Hz}$, which seems to originate from superposition of natural sprung and unsprung masses frequencies from Table 1. This frequency is the most severe one in terms of WBVs in the frequency spectrum since it is close to the thorax's natural frequency $7.38 \mathrm{~Hz}$ (Table 2). However, both seat models successfully attenuate vibrations in this area, with the K-Seat model always achieving it to greater extent. For example, in Figure 9(c), the K-Seat model attenuates the accelerations of around $7 \mathrm{~Hz}$ up to $98 \%(\mathrm{TR}=1.8 \%)$, whereas PS model up to $91 \%$ (TR $=9.1 \%)$. For the other frequencies in the frequency spectrum, it can be seen that in all cases (Figure 9(b, d, e)), K-Seat transmissibility attenuate more the input signal compared to the PS model and tries to convert the low frequencies $(<1 \mathrm{~Hz})$ as the most dominant in the pelvis' vibration signal. The importance of the above results lies upon the fact that these frequencies are out of the important frequency range with respect to comfort $(1-8 \mathrm{~Hz})$ and far away from the natural frequencies of the rest human body parts (Table 2). This is successfully achieved in the case of the driver. In the passengers' cases, the frequencies around $7 \mathrm{~Hz}$ are significantly attenuated compared to the input. Similarly, in this direction, the peaks around the pelvis natural frequency $(\sim 2 \mathrm{~Hz})$ are almost 4 times smaller.

As far as passenger53 is concerned, the $R C$ value of both the seat $(i=s e)$ and the back $(i=2)$ are decreased significantly with the use of the K-seat (77\% and $79 \%$, respectively) (Table 8 ). As a result of the $\sim 77 \%$ decrease in the $R C$ metric of the seat, an "very uncomfortable"

Table 8. Comparison of the optimum design solutions of the two seat models in terms of comfort metrics for passenger53, passenger27 and driver.

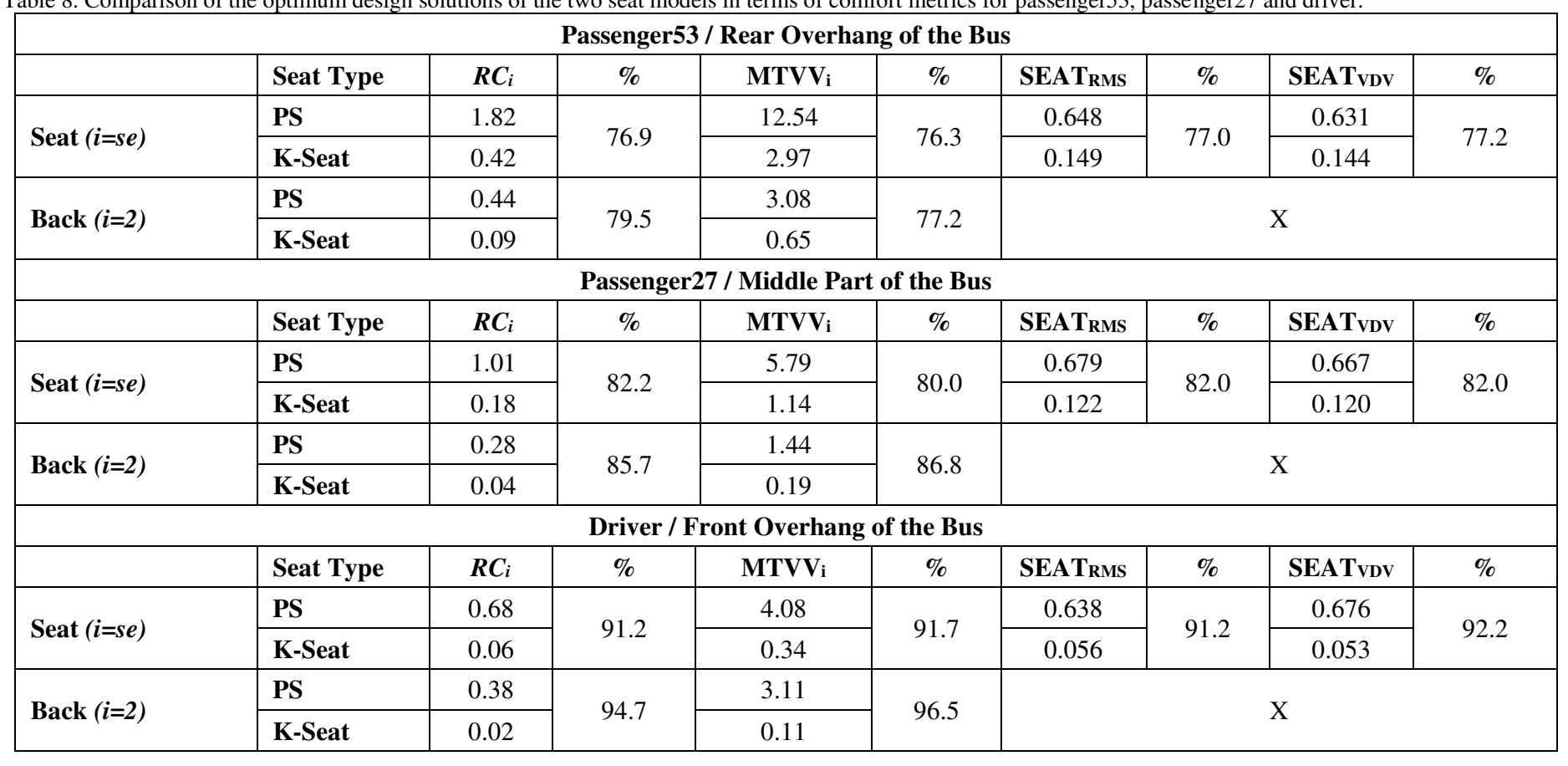




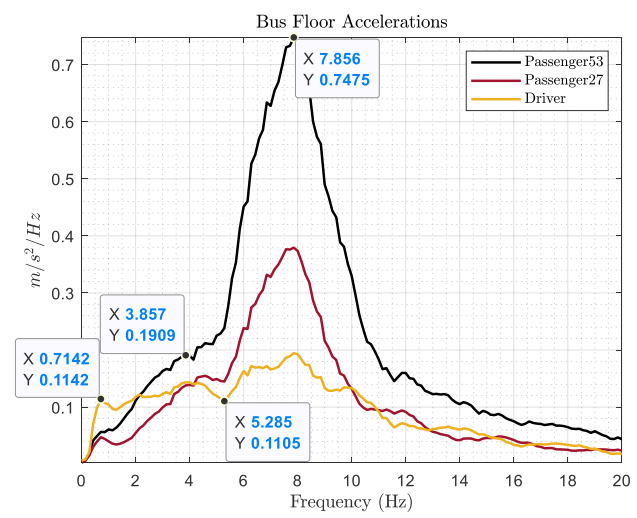

(a)

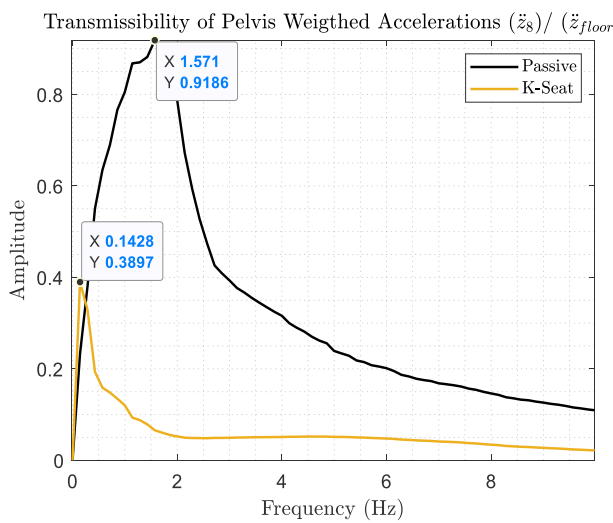

(b)

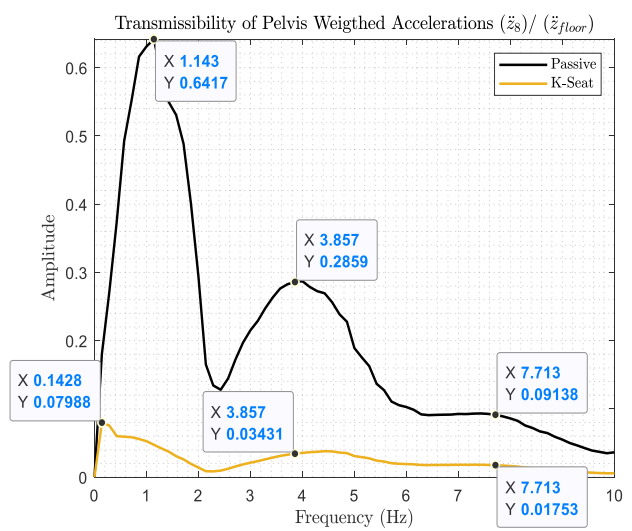

(d)

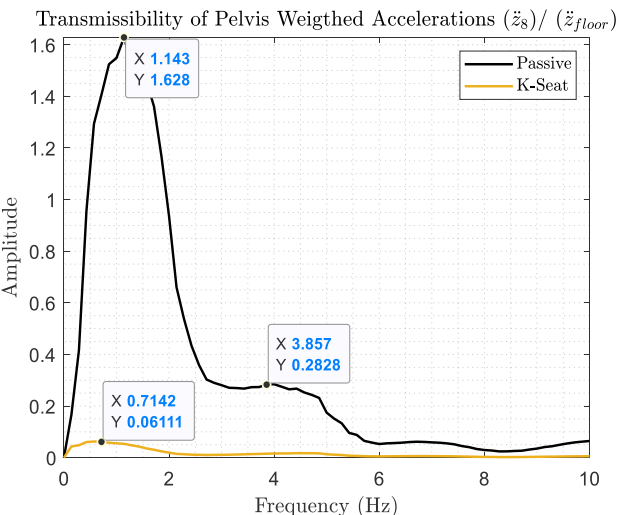

(f)

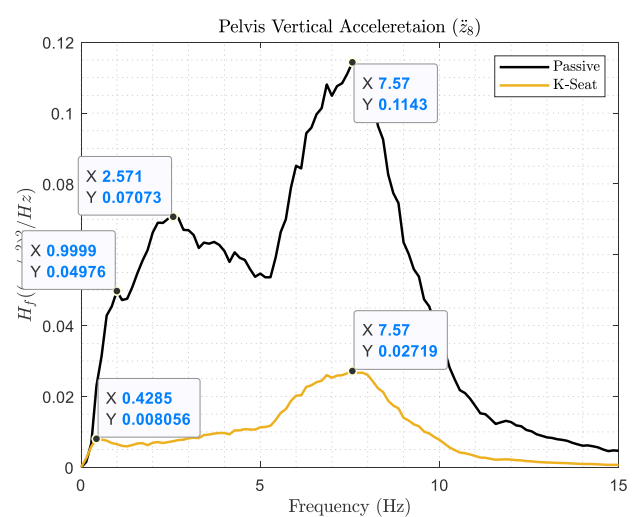

(c)

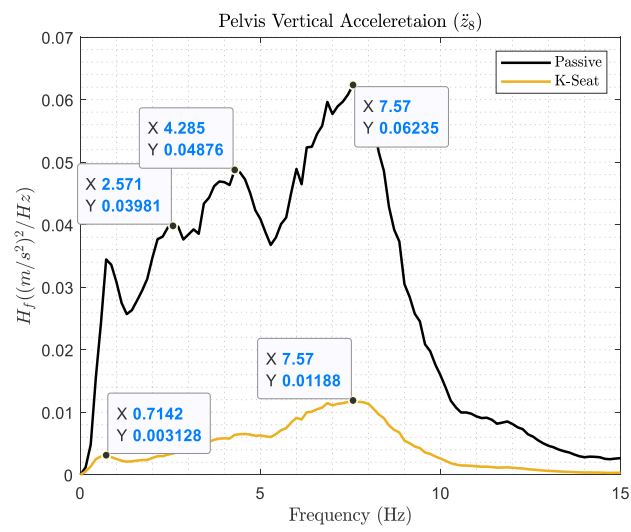

(e)

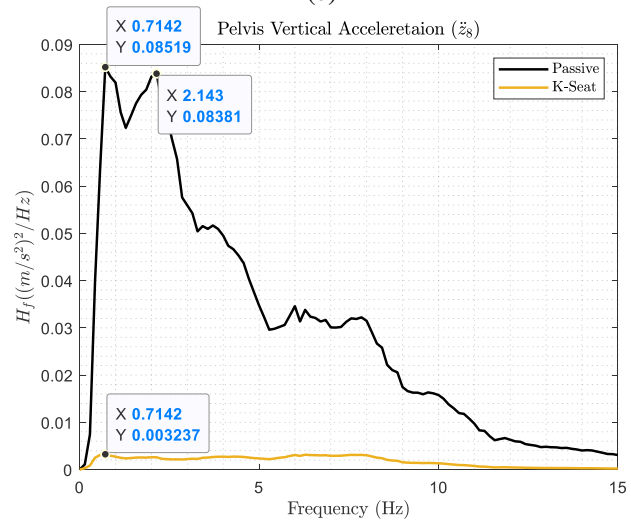

(g)

Figure 9. Bus Floor Accelerations $\left(\ddot{z}_{\text {floor }}\right)$ in Frequency Domain(a) and Transmissibility of Weighted Accelerations to the Pelvis at the positions of (b) Passenger53,

(c) Passenger27 and (d) Driver 


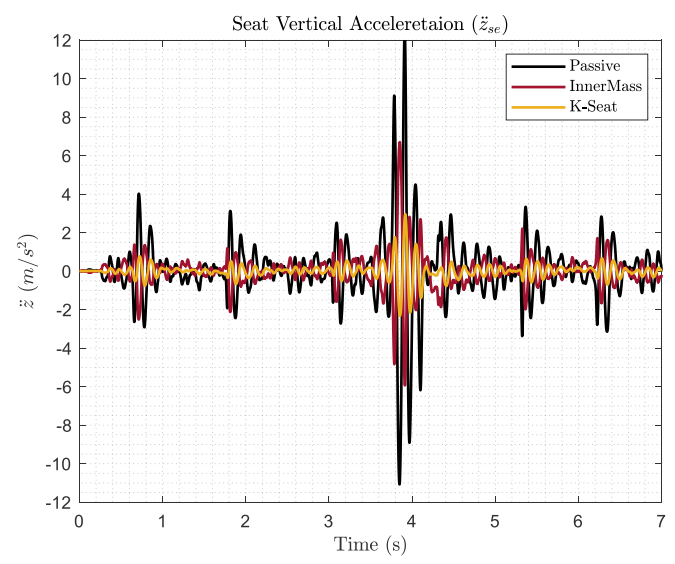

(a)

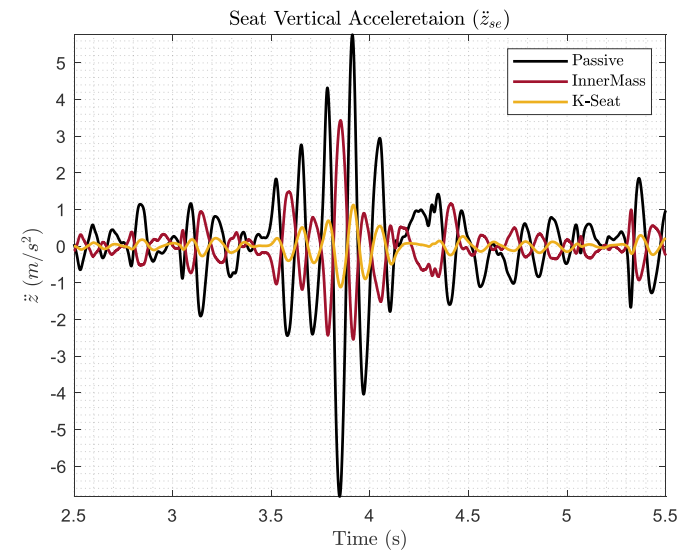

(c)

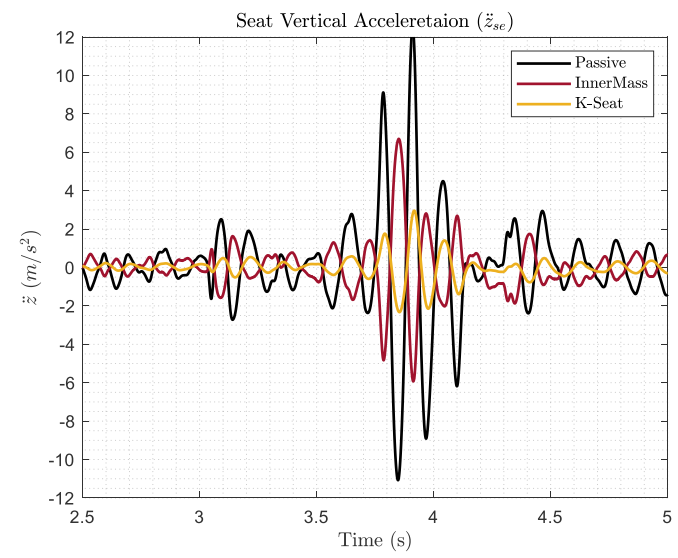

(b)

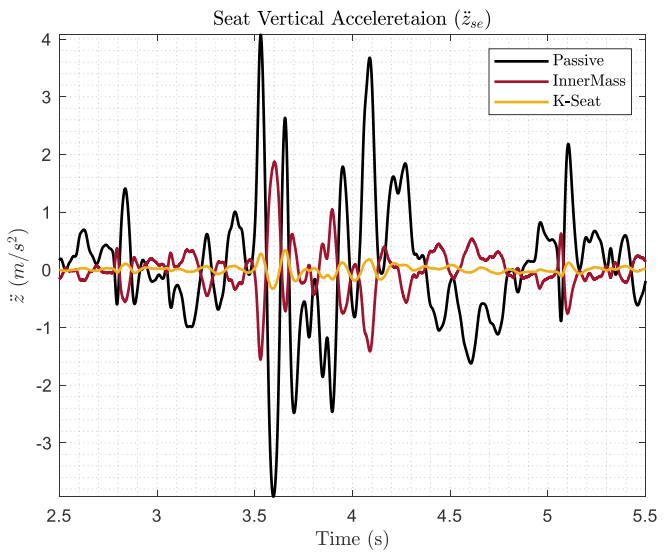

(d)

Figure 10. Seat vertical acceleration $\left(\ddot{z}_{s e}\right)$ at the positions of: (a) passenger53; (b) passenger53 of 2.5-5 sec time interval; (c) passenger27 and (d) driver

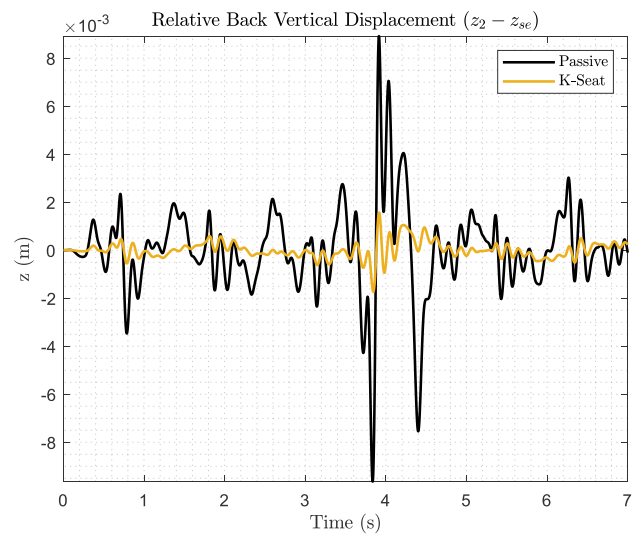

(a)

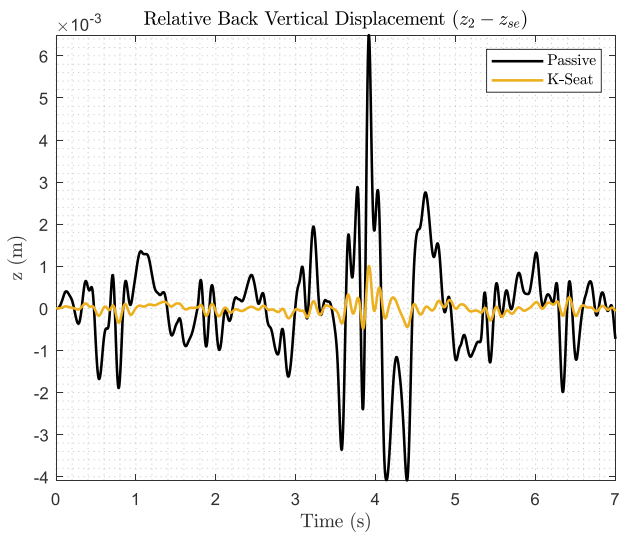

(b)

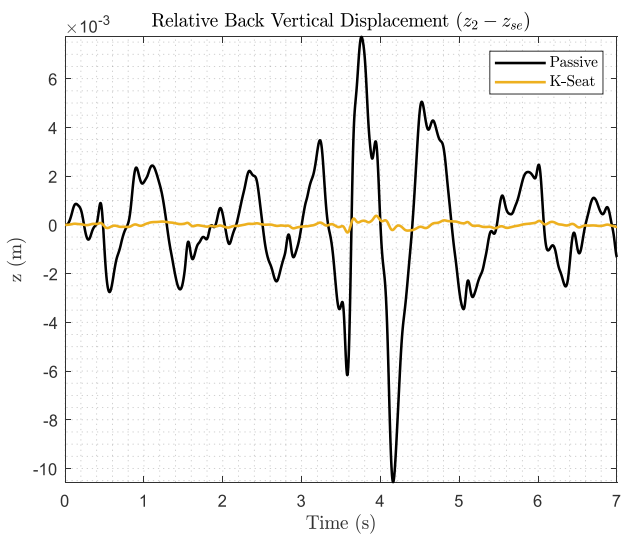

(c)

Figure 11. Relative back displacement (z2-zse) at the positions of: (a) passenger53; (b) passenger27 and (c) driver 
Table 9. Design Variables for PS Model

\begin{tabular}{|l|l|l|l|l|}
\hline & LB & \multicolumn{2}{|c|}{ Optimized Values } & UB \\
\hline \multirow{3}{*}{ Passenger53 } & 300 & $C_{v}[\mathbf{N s} / \boldsymbol{m}]$ & $=0 f 830$ & 2500 \\
\cline { 2 - 5 } & 10000 & $K_{\mathrm{v}}[\mathbf{N} / \mathbf{m}]$ & $=13881$ & 150000 \\
\hline & $\mathrm{LB}$ & \multicolumn{2}{|c|}{ Optimized Values } & UB \\
\hline \multirow{3}{*}{ Passenger27 } & 300 & $\boldsymbol{C}_{\boldsymbol{v}}[\mathbf{N s} / \boldsymbol{m}]$ & $=01004$ & 2500 \\
\cline { 2 - 5 } & 10000 & $K_{\mathrm{v}}[\mathbf{N} / \mathbf{m}]$ & $=14744$ & 150000 \\
\hline \multirow{3}{*}{ Driver } & $\mathrm{LB}$ & \multicolumn{2}{|c|}{ Optimized Values } & UB \\
\hline & 300 & $\boldsymbol{C}_{\boldsymbol{v}}[\mathbf{N s} / \mathbf{m}]$ & $=\mathrm{d} 1021$ & 2500 \\
\cline { 2 - 5 } & 10000 & $\boldsymbol{K}_{\mathrm{v}}[\mathbf{N} / \mathbf{m}]$ & $=14809$ & 150000 \\
\hline
\end{tabular}

Table 10. Design Variables for K-Seat Model

\begin{tabular}{|c|c|c|c|c|}
\hline & LB & \multicolumn{2}{|c|}{ Optimized Values } & UP \\
\hline \multirow{7}{*}{ Passenger53 } & 0.1 & $\alpha_{o}[m]$ & $=0.214$ & 0.4 \\
\hline & 0.1 & $L_{o}[m]$ & $=0.225$ & 0.4 \\
\hline & 0.1 & $b[m]$ & $=0.260$ & 0.4 \\
\hline & 300 & $C_{\mathrm{v}}[\mathrm{Ns} / \mathrm{m}]$ & $=300$ & 1000 \\
\hline & 10000 & $K_{S}[N / m]$ & $=22775$ & 180000 \\
\hline & 2000 & $K_{P}[N / m]$ & $=38470$ & 70000 \\
\hline & 2000 & $K_{h}[N / m]$ & $=\mathrm{j} 6813$ & 70000 \\
\hline & LB & \multicolumn{2}{|c|}{ Optimized Values } & UP \\
\hline \multirow{8}{*}{ Passenger27 } & 0.1 & $\alpha_{o}[m]$ & $=0.252$ & 0.4 \\
\hline & 0.1 & $L_{o}[m]$ & $=0.275$ & 0.4 \\
\hline & 0.1 & $b[m]$ & $=0.397$ & 0.4 \\
\hline & 300 & $C_{\mathrm{v}}[\mathrm{Ns} / \mathrm{m}]$ & $=300$ & 1000 \\
\hline & 10000 & $K_{S}[N / m]$ & $=21982$ & 180000 \\
\hline & 2000 & $K_{P}[N / m]$ & $=41753$ & 70000 \\
\hline & 2000 & $K_{h}[N / m]$ & $=\mathrm{j} 6888$ & 70000 \\
\hline & LB & \multicolumn{2}{|c|}{ Optimized Values } & UP \\
\hline \multirow{7}{*}{ Driver } & 0.1 & $\alpha_{o}[m]$ & $=0.274$ & 0.4 \\
\hline & 0.1 & $L_{o}[m]$ & $=0.274$ & 0.4 \\
\hline & 0.1 & $b[m]$ & $=0.397$ & 0.4 \\
\hline & 300 & $C_{\mathrm{v}}[\mathrm{Ns} / \mathrm{m}]$ & $=300$ & 1000 \\
\hline & 10000 & $K_{S}[N / m]$ & $=22793$ & 180000 \\
\hline & 2000 & $K_{P}[N / m]$ & $=66881$ & 70000 \\
\hline & 2000 & $K_{h}[N / m]$ & $=\mathrm{f} 8519$ & 70000 \\
\hline
\end{tabular}

comfort assessment is transformed to a "a little uncomfortable" according to ISO-2631/1997 criteria (Table 3). This is also illustrated in Figure 10 (a), where vertical accelerations are significantly attenuated comparted to the PS seat. Responsible for the above fact is the inner mass $\left(m_{d}\right)$, which is vibrating in counter-direction with the floor and the mass seat $\left(m_{s e}\right)$, as it can be seen more clearly in Figure 10(b). As a result, the vibrations of the $m_{s e}$ are attenuated to a great extent. In accordance to the above, the MTVV values of the seat are also decreased around $\sim 76 \%$, showing that the K-seat isolates the high-level accelerations experienced by the passengers in the rear overhang of the bus. Similar reductions $(\sim 79 \%)$ are identified also in the back (m2) of passenger53. K-Seat model has proven to be $77 \%$ more efficient in attenuating the input floor vibrations regardless their peaks, according to the SEATRMS ( 0.149, i.e., attenuation of vibrations at $85.1 \%)$ and SEATVDV ( 0.144, i.e., attenuation of vibrations at $85.6 \%)$. Attenuation in vertical acceleration peaks is important since high peaks values could cause spine injures in passengers seating in the rear part.

Similar conclusions could be extracted for passenger27, as the RC value of both the seat and the back are decreased around 82-86\%, with the efficiency of the K-Seat model to be greater than the PS model around $82 \%$. As a result, "uncomfortable" comfort assessment, in the PS case, is transformed to a "comfortable" according to ISO2631/1997 criteria, when the K-Seat is applied. Moreover, in the position of passenger27 as well as in the one of passenger53, the insignificant difference between SEATRMS and SEATVDV in the case of K-seat, outlines the ability of the proposed suspension system to isolate the peaks of the floor vibration in both positions.

Regarding the driver, the decrease in the studied metrics is greater comparing to passengers' cases (passenger53 and passenger27), being between $91-97 \%$. More specifically, in the PS case, the driver feels "fairly uncomfortable" during the ride, whereas in the K-Seat case, the ride is "comfortable". Also, the fact that the efficiency of the K-Seat model in terms of isolation is greater than the PS model around $91.2 \%$ according to the SEATRMS and the SEATVDV values, affects the vibration levels in the driver's back. In particular, the K-seat attenuates $94.4 \%$ of the vibrations (SEATRMS 0.056), while the PS only $36.2 \%$ (SEATRMS 0.638). As a result, the RC and the MTVV values in the driver back are decreased $94.5 \%$ and $96.5 \%$, respectively, compared to the PS case, implying a significant possible improvement in the low-back pains of the driver. The above argument is also depicted in Figure 10(c), where the driver's back relative displacement is almost insignificant when the K-Seat model is used.

\section{Conclusions}

This paper investigated the application of a seat suspension design with embedded negative stiffness elements in order to reduce the low-back pains experienced by the bus drivers and reduce the highlevel accelerations experienced by the rear row passengers. The results illustrated both a possible significant decrease in the driver's low back pains and an improvement of passengers' comfort compared to the conventional seat design.

Simulation results showed that vertical weighted acceleration at the users' seats and their backs were significantly of the much lower values for the K-seat than for the passive seat. Based on the results, the K-Seat improves significantly the comfort of the users ( $92 \%)$ compared to the PS, while it achieves similar decrease in the maximum values of the user's back accelerations ( $97 \%)$. More specifically, for a passenger in the rear part of the bus, weighted acceleration for K-seat was $0.42 \mathrm{~m} / \mathrm{s}^{2}$ corresponding to "a little uncomfortable" comfort assessment, whereas for the passive seat it was high value of $1.82 \mathrm{~m} / \mathrm{s}^{2}$ which is "very uncomfortable" comfort. $\mathrm{K}$-seat also isolates the high-level accelerations experienced by the bus users, which is important since high peaks values could cause low-back injures especially for the passengers seating in the rear part. These results proved promising for investigating further the application of seat-suspensions with embedded negative stiffness elements in bus seats, at least in positions/rows where issues have identified in the literature (driver and rear overhang).

Although, investigation at this stage considered vibration in vertical direction only, for future work seat-human models will be adopted to also analyse vibrations in horizontal directions (x, $\mathrm{y}$ - directions). Furthermore, future work will be concentrated on comparative analysis of ride comfort performance for $\mathrm{K}$-seat and passive seat for 
other exploitation conditions such as, different bus loadings (e.g. empty/partly/fully loaded), different bus speeds (e.g. 60, 80, 100, 120 $\mathrm{km} / \mathrm{h}$ ), road roughness inputs of different type and quality (e.g. medium/good asphalt-concrete road, etc.).

\section{References}

[1] E. Johanning, "Whole-body vibration-related health disorders in occupational medicine-an international comparison," Ergonomics, vol. 58, no. 7, pp. 1239-1252, 2015.

[2] M. A. J. Kompier and V. Di Martino, "Review of bus drivers' occupational stress and stress prevention," Stress Med., vol. 11, no. 1, pp. 253-262, 1995.

[3] M. J. Griffin, "Discomfort from feeling vehicle vibration," Veh. Syst. Dyn., vol. 45, no. 8, pp. 679-698, 2007.

[4] P. K. Patterson, Tammy Lynn Eubanks, and Roxanne Ramseye, "Back Discomfort Prevalence: And Associated Factors among Bus Drivers," AAOHN J., vol. 34, no. 10, pp. 481-484, 1986.

[5] E. Johanning, "Back disorder intervention strategies for mass transit operators exposed to whole-body vibration Comparison of two transit system approaches and practices," J. Sound Vib., vol. 215, no. 4, pp. 629-634, Aug. 1998.

[6] M. Bovenzi et al., "An epidemiological study of low back pain in professional drivers," J. Sound Vib., vol. 298, no. 3, pp. 514-539, Dec. 2006.

[7] D. Alperovitch-Najenson, Y. Santo, Y. Masharawi, M. KatzLeurer, D. Ushvaev, and L. Kalichman, "Low back pain among professional bus drivers: ergonomic and occupational-psychosocial risk factors," Isr. Med. Assoc. J., vol. 12 , no. 1 , pp. $26-31,2010$.

[8] C. A. Lewis and P. W. Johnson, "Whole-body vibration exposure in metropolitan bus drivers," Occup. Med. (Chic. Ill)., vol. 62, pp. 519-524, 2012.

[9] D. Sekulić, V. Dedović, S. Rusov, S. Šalinić, and A. Obradović, "Analysis of vibration effects on the comfort of intercity bus users by oscillatory model with ten degrees of freedom," Appl. Math. Model., vol. 37, no. 18-19, pp. 86298644, Oct. 2013.

[10] D. Sekulić, V. Dedović, S. Rusov, A. Obradović, and S. Šlinić, "Definition and determination of the bus oscillatory comfort zones," Int. J. Ind. Ergon., vol. 53, pp. 328-339, May 2016.

[11] I. Maciejewski, L. Meyer, and T. Krzyzynski, "Modelling and multi-criteria optimisation of passive seat suspension vibro-isolating properties," J. Sound Vib., 2009.

[12] M. Gohari, R. A. Rahman, M. Tahmasebi, and P. Nejat, "Off-road Vehicle Seat Suspension Optimisation, Part I: Derivation of an Artificial Neural Network Model to Predict Seated Human Spine Acceleration in Vertical Vibration," J. Low Freq. Noise, Vib. Act. Control, vol. 33, no. 4, pp. 429442, 2014.

[13] J. Ho Bang, C. A. Lee, H. Y. Kim, H. J. Kim, and K. Y. Choi, "Optimization of the static properties of seat foam to improve the seating comfort," Proc. Inst. Mech. Eng. Part D J. Automob. Eng., 2016.

[14] W. Sun, W. T. Xu, J. H. Lin, D. Kennedy, and F. W. Williams, "Ride-comfort-oriented suspension optimization using the pseudo-excitation method," Proc. Inst. Mech. Eng. Part D J. Automob. Eng., 2010.

[15] Haiping Du, Weihua Li, and Nong Zhang, "Integrated Seat and Suspension Control for a Quarter Car With Driver Model," IEEE Trans. Veh. Technol., vol. 61, no. 9, pp. 3893-3908, Nov. 2012.

[16] H. J. Yao, J. Fu, M. Yu, and Y. X. Peng, "Semi-active $\mathrm{H} \infty$ control of seat suspension with MR damper," J. Phys. Conf. Ser., vol. 412, no. 1, 2013.

[17] D. Ning, S. Sun, J. Zhang, H. Du, W. Li, and X. Wang, "An active seat suspension design for vibration control of heavyduty vehicles," J. Low Freq. Noise, Vib. Act. Control, 2016. Y. Zhao and X. Wang, "A Review of Low-Frequency Active Vibration Control of Seat suspension Systems," Appl. Sci., vol. 9, no. 16, p. 3326, Aug. 2019.

[19] R. P. Blood, J. D. Ploger, M. G. Yost, R. P. Ching, and P. W. Johnson, "Whole body vibration exposures in metropolitan bus drivers: A comparison of three seats," $J$. Sound Vib., vol. 329, no. 1, pp. 109-120, Jan. 2010.

[20] R. P. Blood, M. G. Yost, J. E. Camp, and R. P. Ching, "Whole-body vibration exposure intervention among professional bus and truck drivers: A laboratory evaluation of seat-suspension designs," J. Occup. Environ. Hyg., vol. 12, no. 6, pp. 351-362, Jun. 2015.

[21] O. Thamsuwan, R. P. Blood, C. Lewis, P. W. Rynell, and P. W. Johnson, "Whole Body Vibration Exposure and Seat Effective Amplitude Transmissibility of Air Suspension Seat in Different Bus Designs," in PROCEEDINGS of the HUMAN FACTORS and ERGONOMICS SOCIETY 56th ANNUAL MEETING, 2012.

[22] T. D. Le and K. K. Ahn, "A vibration isolation system in low frequency excitation region using negative stiffness structure for vehicle seat," J. Sound Vib., 2011.

[23] T. D. Le and K. K. Ahn, "Active pneumatic vibration isolation system using negative stiffness structures for a vehicle seat," J. Sound Vib., vol. 333, no. 5, pp. 1245-1268, Feb. 2014.

[24] T. D. Le and K. K. Ahn, "Experimental investigation of a vibration isolation system using negative stiffness structure," Int. J. Mech. Sci., vol. 70, pp. 99-112, 2013.

[25] X. Wang, H. Liu, Y. Chen, and P. Gao, "Beneficial stiffness design of a high-static-low-dynamic-stiffness vibration isolator based on static and dynamic analysis," Int. J. Mech. Sci., vol. 142-143, pp. 235-244, Jul. 2018.

[26] J. Zhou, X. Wang, D. Xu, and S. Bishop, "Nonlinear dynamic characteristics of a quasi-zero stiffness vibration isolator with cam-roller-spring mechanisms," J. Sound Vib., vol. 346, no. 1, pp. 53-69, 2015.

[27] Z. Yan, B. Zhu, X. Li, and G. Wang, "Modeling and analysis of static and dynamic characteristics of nonlinear seat suspension for off-road vehicles," Shock Vib., vol. 2015, 2015.

[28] L. Zhao, Y. Yu, C. Zhou, and F. Yang, "Modelling and validation of a seat suspension with rubber spring for offroad vehicles," JVC/Journal Vib. Control. Vib. Control, 2017.

[29] G. Papaioannou, A. Voutsinas, D. Koulocheris, and I. Antoniadis, "Dynamic performance analysis of vehicle seats with embedded negative stiffness elements," Veh. Syst. Dyn., vol. 58, no. 2, pp. 307-337, Feb. 2020.

[30] G. Papaioannou, A. Voutsinas, and D. Koulocheris, "Optimal design of passenger vehicle seat with the use of negative stiffness elements," Proc. Inst. Mech. Eng. Part D J. Automob. Eng., 2019.

[31] D. Sekulić, S. Rusov, V. Dedović, S. Šalinić, D. Mladenović, and I. Ivković, "Analysis of bus users' vibration exposure time," Int. J. Ind. Ergon., vol. 65, pp. 2635, May 2018.

[32] I. A. Antoniadis, S. A. Kanarachos, K. Gryllias, and I. E. Sapountzakis, "KDamping: A stiffness based vibration absorption concept," JVC/Journal Vib. Control, vol. 24, no. 3, pp. 588-606, 2016.

[33] D. Koulocheris, G. Papaioannou, and D. Christodoulou, "An approach for multi-objective optimization of vehicle 
suspension system," IOP Conf. Ser. Mater. Sci. Eng., vol. 252, no. 1, 2017.

[34] C.-C. Liang and C.-F. Chiang, "A study on biodynamic models of seated human subjects exposed to vertical vibration," Int. J. Ind. Ergon., vol. 36, no. 10, pp. 869-890, Oct. 2006.

[35] G. Papaioannou and D. Koulocheris, “An approach for minimizing the number of objective functions in the optimization of vehicle suspension systems," J. Sound Vib., Aug. 2018.

[36] S. A. Adam and N. A. A. Jalil, "Vertical Suspension Seat Transmissibility and SEAT Values for Seated Person Exposed to Whole-body Vibration in Agricultural Tractor Preliminary Study," Procedia Eng., vol. 170, pp. 435-442, 2017.

[37] D. Sekulic, I. Ivkovic, and D. Mladenovic, "Effects of the seat cushion oscillatory parameters on vibration exposure and dynamic seat comfort in the bus," J. Appl. Eng. Sci., vol. 15, no. 4, pp. 433-441, 2017. 


\section{Investigation of seat suspensions with embedded negative stiffness elements} pÿfor isolating bus users whole-body vibrations

\section{Papaioannou, Georgios}

Society of Automotive Engineers

Papaioannou G, Sekulic D, Velenis E, Antoniadis I. (2021) Investigation of seat suspensions pÿwith embedded negative stiffness elements for isolating bus users whole-body vibrations. SAE Technical Papers, Paper number 2021-01-5019, February 2021

https://doi.org/10.4271/2021-01-5019

Downloaded from Cranfield Library Services E-Repository 